\title{
Expert System Logika Fuzzy Penentuan Proses Penanaman Bibit Unggul Kayu Manis dengan Metode Mamdani
}

\author{
Silvilestari \\ Manajemen Informatika, AMIK Kosgoro, Solok, Sumatera Barat, Indonesia \\ Email: rendanghjfatimah@gmail.com \\ Email Penulis Korespondensi: rendanghjfatimah@gmail.com \\ Submitted: 10/12/2021; Accepted: 25/12/2021; Published: 31/12/2021
}

\begin{abstract}
Abstrak-Kayu manis merupakan tumbuhan yang banyak di minati orang karena kayu manis memiliki nilai jual yang tinggi. Kayu manis memiliki dua ke untungan jika sudah tumbuh menjadi besar yaitu kulit dan kayu nya bisa dipasarkan dengan harga yang tinggi. Saat ini banyak masyarakat meneman kayu manis untuk menunjang kebutuhan di masa yang akan datang. Permasalahan penelitian ini berupa kurangnya informasi dan pemahaman masyarakat dalam memilih kayu manis yang cocok ditanam agar tumbuh subur dan memiliki kualitas yang baik. Tujuan Penelitian ini membentu masyarakat dalam memilih bibit unggul yang bagus untuk ditanam. Penyelesaian kasus ini menggunakan expert metode Sugeno, Proses penyelesaian metode Mamdani menggunakan Operator OR. Proses kerja metode sugeno adalah fuzifikasi, mesin inferensi, Aplikasi fungsi implikasi dan yang terakhir adalah defuzifikasi.Dengan adanya sistem pengambilan keputusan dalam pemilihan bibit unggul kayu manis, diharapkan dapat membantu dan mempermudah masyarakat pada pengambilan keputusan dalam memilih bibit unggul dengan hasil yang lebih akurat. Hasil dari penelitian ini yaitu berupa prototype dengan proses input berupa lahan tanaman, bibit kayu manis, proses penanaman tunas, dan pemeliharaan kayu manis menjadi output berupa hasil keputusan yaitu Sangat Memuaskan, memuaskan dan Tidak Memuaskan.
\end{abstract}

Kata Kunci: Kayu Manis; Pemilihan Bibit Unggul; Expert Sistem; Metode Mamdani

Abstract-Cinnamon is a plant that many people are interested in because cinnamon has a high selling value. Cinnamon has two advantages when it grows big, namely the bark and the wood can be marketed at a high price. Currently, many people are friends with cinnamon to support future needs. The problem of this research is the lack of information and understanding of the community in choosing cinnamon that is suitable for planting so that it thrives and has good quality. The purpose of this research is to help the community in choosing good seeds for planting. The settlement of this case uses the expert method of Mamdani, the process of solving the Mamdani method uses the OR operator. The working process of the Mamdani method is fuzification, inference engine, application of implication functions and the last is defuzification. With the decision-making system in selecting superior cinnamon seeds, it is hoped that it can help and facilitate the community in making decisions in choosing superior seeds with more accurate results. The results of this study are in the form of a prototype with the input process in the form of planting land, cinnamon seeds, the process of planting shoots, and maintaining cinnamon as output in the form of decisions, namely Very Satisfactory, Satisfactory and Unsatisfactory.

Keywords: Superior Cinnamon Seedlings; Selection of Superior Seeds; Expert System; Mamdani Method

\section{PENDAHULUAN}

Kulit manis merupakan salah satu jenis rempah-rempahan yang berumur panjang. Tanaman kulit manis dengan nama lain Cassiavera sudah lama dikenal oleh masyarakat dunia, di Mesir Kuno misalnya kulit manis digunakan untuk membalsem mayat, dan untuk obat-obatan.1 Dalam buku Kulit Manis Budidaya dan Pengolahan disebutkan bahwa jenis tanaman cassiavera merupakan substansi nabati termasuk juga jenis rempah lain seperti cengkeh, pala, lada dan lainnya yang dimanfaatkan untuk meningkatkan cita rasa makanan, kosmetik dan sebagai rempah penyembuh.2 Kulit manis pertama kali diperkenalkan di Indonesia oleh L.P.J. Du Busde Gissignies, Gubernur Jendral Hindia Belanda pada tahun 1825.3 Pada mulanya kulit manis di Sumatera Barat terdapat di daerah Kamang, Pandai Sikek dan Koto Laweh.4 Tidak ada informasi tentang orang yang pertama kali membawa kulit manis ke Sumatera Barat. Kemudian kulit manis ini ditanam di daerah lain di Sumatera Barat, salah satunya Nagari Andaleh, Kecamatan Batipuh, Kabupaten Tanah Datar. Logika Fuzzy adalah Sebuah system Pemecahan masalah yang cocok dalam sebuah system. Dimulai dari hal yang kecil,sederhana dan penyebaran nya secara luas. Bisa dijadikan acuan dalam pemecahan masalah untuk mengambil sebuah keputusan[1].

Logika fuzzy adalah suatu cara yang tepat untuk memetakan suatu ruang input kedalam suatu ruang output. Titik awal dari konsep modern mengenai ketidakpastian adalah paper yang dibuat oleh Lofti A Zadeh (1965), dimana Zadeh memperkenalkan teori yang memiliki obyek-obyek dari himpunan fuzzy yang memiliki batasan yang tidak presisi dan keanggotaan dalam himpunan fuzzy, dan bukan dalam bentuk logika benar (true) atau salah (false), tapi dinyatakan dalam derajat (degree). Konsep seperti ini disebut dengan Fuzziness dan teorinya dinamakan Fuzzy Set Theory[2].Logika fuzzy memiliki kelebihan [3] diantaranya:

a) Pemahaman pada logika fuzzy menggunakan konsep yang sangat mudah dan sederhana untuk dimengerti;

b) Sangat Fleksibel;

c) Memiliki sebuah toleransi dalam data data;

d) Mampu membuat fungsi fungsi non linear dengan lengkap;

e) Bisa mengimplementasikan pengala-man para pakar tampa melakukan sebuah pelatian terlebih dahulu;

f) Sistem fuzzy sudah melakukan kerjasama mengunakan teknik kendali dengan konvensional;

g) Sistem Fuzzy menggunakan bahasa alami. 
Building of Informatics, Technology and Science (BITS)

Volume 3, No 3, December 2021, Page 141-147

ISSN 2684-8910 (media cetak)

ISSN 2685-3310 (media online)

DOI 10.47065/bits.v3i3.1014

Fuzziness dapat didefinisikan sebagai logika kabur berkenaan dengan semantik dari suatu kejadian, fenomena atau pernyataan itu sendiri. Seringkali ditemui dalam pernyataan yang dibuat oleh seseorang, evaluasi dan suatu pengambilan keputusan[4]. Teori himpunan Fuzzy adalah merupakan perluasan dari teori logika Boolean yang menyatakan tingkat angka 1 atau 0 atau pernyataan benar atau salah, sedang pada teori logika Fuzzy terdapat tingkat nilai, yaitu:

a) Satu (1), yang berarti bahwa suatu item menjadi anggota dalam suatu himpunan, ;

b) Nol (0), yang berarti bahwa suatu item tidak menjadi anggota dalam suatu himpunan[5].Fuzzy infernce system memiliki 3 operator untuk mendapatkan nilai output.

c) Tiga operator yang dimiliki diantaranya [6]: 1.Operator or 2. Operator and 3.Operator not.

Model fuzzy / linguistik sejak awal dikembangkan dengan menggunakan logika formal. Namun, formulasi asli berdasarkan versi predikat dari, disebut demikian, logika fuzzy dengan sintaks yang dievaluasi ternyata tidak memuaskan secara rapi. Perumusan baru yang menggunakan bahasa logika fuzzy matematika tingkat tinggi jauh lebih sesuai dan transparan [7] Pada sistem inferensi fuzzy bisa dijadikan sebagai sistem pengendali untuk aturan aturan fuzzy tersebut[8]. Berdasarkan penelitian [9] Metode Mamdani merupakan sebuah metode yang pupuler saat ini, metode ini memakai nilai terbesar-terkecil atau lebih dikenal dengan istilah max-min untuk memperoleh nilai output. Sehingga dapat disimpulkan bahwa metode fuzzy mamdani adalah merupakan salah satu metode yang sering digunakan untuk memprediksi stok persediaan barang dalam suatu perusahaan[10]. Fuzzy logic merupakan sistem yang dapat menghitung dan memutuskan dengan baik. Fuzzy Logic atau Logika Fuzzy merupakan salah satu metode untuk menentukan sebuah keputusan. Himpunan adalah suatu kumpulan ataukoleksi objek-objek yang mempunyaikesamaan sifat tertentu.Himpunan fuzzy merupakan suatu pengembangan lebih lanjut tentang konsep himpunan dalam matematika. Himpunan fuzzy adalah rentang nilai-nilai, masing-masing nilai mempunyai derajat keanggotaan antara 0 sampai dengan 1[11].Menurut [12] pada himpunan tegas (crisp), nilai keanggotaan suatu intem $\mathrm{x}$ dalam suatu himpunan $\mathrm{A}$, yang sering ditulis dengan $\mu \mathrm{A}[\mathrm{x}]$ memiliki dua kemungkinan, yaitu: Satu (1), yang berarti bahwa suatu intem menjadi anggota dalam satu himpunan.Nol (0) yang berarti bahwa suatu intem tidak menjadi anggota dalam suatu himpun. Banyak jurnal yang menjelaskan bahwa metode Mamdani dapat digunakan dalam berbagai bidang[13],[14],[15],[16].

\section{METODOLOGI PENELITIAN}

\subsection{Tahapan Penelitian}

Metode penelitian adalah gambaran tentang penelitian yang akan dilaksanakan. Langkah langkah penelitian yang akan dilaksanakan diantaranya:

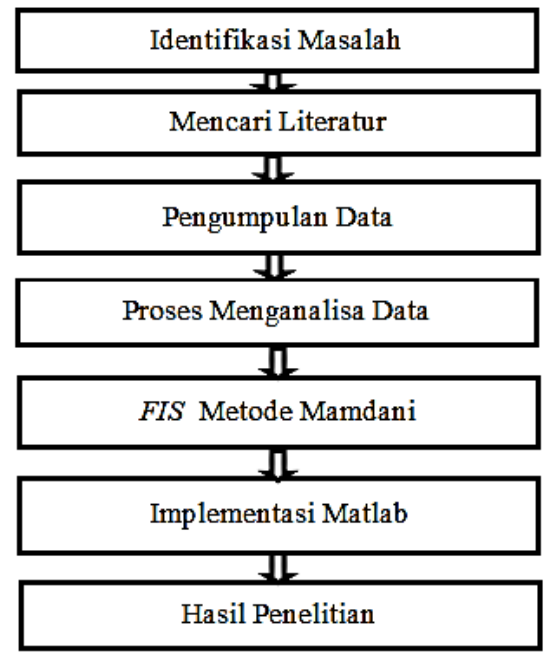

Gambar 1. Desain Penelitian

\subsection{Rancangan Logika Fuzzy}

Metode yang digunakan dalam penelitian ini adalah metode Mamdani atau sering dikenal sebagai metode Max-Min. Langkah-langkah dalam analisis data Metode Mamdani pada penelitian ini adalah sebagai berikut:

a) Pembentukan himpunan fuzzy

Sebelum dilakukan analisis data, data nilai yang ada di transformasikan ke dalam satu nilai. Dalam pembentukan fuzzy, fungsi keanggotaan yang digunakan adalah fungsi sigmoid, fungsi phi, fungsi segitiga, dan fungsi trapesium.

b) Aplikasi fungsi implikasi 
Sebelum masuk ke fungsi implikasi, ditentukan rule-nya terlebih dahulu. Secara umum, rules dibuat pakar secara intuitif. Rules berupa pernyataan-pernyataan kualitatif yang ditulis dalam bentuk if then, sehingga mudah dimengerti.

c) Komposisi aturan

Metode maksimum dalam FIS dalam pembentukan rulu dengan perkalian matriks.

d) Penegasan (defuzzifikasi)

Defuzzifikasi adalah cara untuk memperoleh nilai tegas (crisp) dari himpunan fuzzy. Metode Centroid (composite moment) digunakan penentuan gaji tunjangan yang layak kepada karyawan. Pada metode ini, penegasan diperoleh dengan cara mengambil titik pusat $\left(\mathrm{z}^{*}\right)$ daerah fuzzy.

\subsection{Metode Mamdani}

Metode Mamdani sering dikenal sebagai Metode Max-Min. Pembentukan himpunan fuzzy.. Secara umum dirumuskan:

$$
Z^{*}=\frac{\int_{Z} 2 \mu(z) d z}{\int_{Z} \mu(z) d z}
$$

\section{HASIL DAN PEMBAHASAN}

Variabel harus didefinisikan secara operasional agar lebih mudah dicari hubungannya antara satu variabel dengan lainnya dan pengukurannya. Proses fuzzy diawali dengan pemilihan variabel fuzzy yang selanjutnya pembentukan himpunan fuzzy yang mewakili suatu kondisi variabel fuzzy, semesta pembicaraan dan domain himpunan fuzzy. Variabel-variabel fuzzy terdiri dari variabel input dan variabel output. Variabel input yang digunakan dalam penelitian ini terdiri dari Lahan tanaman, bibit kayu manis, proses penanaman tunas, dan pemeliharaan kayu manis menjadi output berupa hasil keputusan yaitu Sangat Memuaskan, memuaskan dan Tidak Memuaskan. Berikut ini adalah tabel himpunan fuzzy dan domain himpunan fuzzy variabel input dan output yang digunakan dalam penelitian.

Tabel 1. Himpunan Fuzzy

\begin{tabular}{clc}
\hline Fungsi & \multicolumn{1}{c}{ Variabel } & Semesta Pembicaraan \\
\hline Input & Lahan Tanaman & $0-50$ \\
& Bibit Kayu Manis & $0-70$ \\
& Proses Penanaman Tunas & $0-100$ \\
& Pemeliharaan Kayu Manis & $0-120$ \\
\hline
\end{tabular}

Tabel 2. Operasional Variabel

\begin{tabular}{|c|c|c|c|c|}
\hline Variabel & Indikator & Himpunan Fuzzy & Semesta Pembicaraan & Domain \\
\hline \multirow[t]{10}{*}{ Input } & Lahan Tanaman & Luas & $0-50$ & {$\left[\begin{array}{lll}0 & 20 & 30\end{array}\right]$} \\
\hline & & Sedang & & {$\left[\begin{array}{lll}25 & 35 & 50\end{array}\right]$} \\
\hline & Bibit Kayu Manis & Super & $0-70$ & {$\left[\begin{array}{lll}0 & 5 & 20\end{array}\right]$} \\
\hline & & Sedang & & {$\left[\begin{array}{llll}16 & 35 & 50\end{array}\right]$} \\
\hline & & Biasa & & {$\left[\begin{array}{llll}45 & 60 & 70\end{array}\right]$} \\
\hline & Proses Penanaman Tunas & Lihat Kondisi Bibit & $0-100$ & {$\left[\begin{array}{lll}0 & 35 & 55\end{array}\right]$} \\
\hline & & Langsung & & {$\left[\begin{array}{llll}50 & 70 & 100\end{array}\right]$} \\
\hline & Pemeliharaan Kayu Manis & Rutin & $0-120$ & {$\left[\begin{array}{lll}0 & 35 & 50\end{array}\right]$} \\
\hline & & Jarang & & {$\left[\begin{array}{lll}45 & 65 & 85\end{array}\right]$} \\
\hline & & Tidak Pernah & & {$\left[\begin{array}{llll}80 & 100 & 120\end{array}\right]$} \\
\hline \multirow[t]{3}{*}{ Output } & Hasil & Sangat Memuaskan & $0-100$ & {$\left[\begin{array}{lll}0 & 25 & 40\end{array}\right]$} \\
\hline & & Memuaskan & & {$\left[\begin{array}{lll}35 & 55 & 75\end{array}\right]$} \\
\hline & & Tidak Memuaskan & & {$\left[\begin{array}{lllll}70 & 85 & 100\end{array}\right]$} \\
\hline
\end{tabular}

Berdasarkan domain himpunan fuzzy yang telah ditentukan, selanjutnya adalah menentukan fungsi keanggotaan variabel input dan output. Fungsi keanggotaan digunakan untuk menghitung derajat keanggotaan variabel input yang memiliki interval 0 dan 1. Fungsi keanggotaan terdiri dari berbagai tipe. Penulis menggunakan 3 fungsi keanggotaan, yaitu fungsi kurva segitiga, kurva trapesium, dan kurva bahu. Berikut adalah fungsi keanggotaan variabel input dan output.

a) Lahan Tanaman terdiri dari 2 himpunan fuzzy, yaitu Luas dan Sedang. Fung keanggotaan untuk variabel Lahan Tanaman dirumuskan sebagai berikut.

$\mu$ Luas[x]

$$
\begin{aligned}
& =\left\{\begin{array}{ccr}
1 & ; \quad x \leq 20 \\
\frac{30-x}{30-20} & ; 20 \leq x \leq 30 \\
0 & ; \quad x \geq 30
\end{array}\right. \\
& \mu \text { Sedang }[x]
\end{aligned}
$$


Building of Informatics, Technology and Science (BITS)

Volume 3, No 3, December 2021, Page 141-147

ISSN 2684-8910 (media cetak)

ISSN 2685-3310 (media online)

DOI 10.47065/bits.v3i3.1014

$$
=\left\{\begin{array}{llr}
0 & ; & x \leq 30 \\
\frac{x-30}{40-30} & ; & 30 \leq x \leq 40 \\
1 & ; & x \geq 40
\end{array}\right.
$$

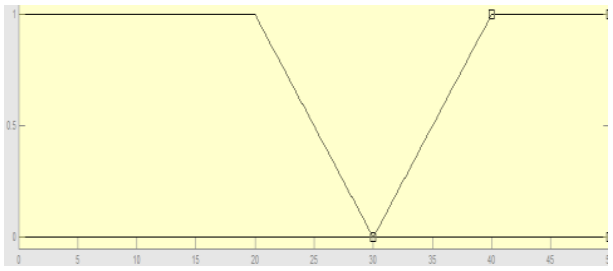

Gambar 2. Fungsi Keanggotaan Variabel Lahan Tanaman

b) Bibit Kayu Manis terdiri dari 3 himpunan fuzzy, yaitu Super, Sedang, dan Biasa. Fungsi keanggotaan untuk variabel Bibit Kayu Manis dirumuskan sebagai berikut.

$\mu$ Biasa[x]

$= \begin{cases}0 & ; \mathrm{x} \leq 20 \text { atau } \mathrm{x} \geq 50 \\ \frac{\mathrm{x}-20}{35-20} & ; 20 \leq \mathrm{x} \leq 35 \\ \frac{50-\mathrm{x}}{50-35} & ; 35 \leq \mathrm{x} \leq 50\end{cases}$

$\mu \_$Sedang $[\mathrm{x}]$

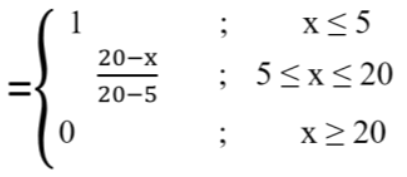

$\mu$ Super[x]

$= \begin{cases}0 & ; x \leq 50 \\ \frac{x-50}{60-50} & ; 50 \leq x \leq 60 \\ 1 & ; 60 \leq x \leq 70\end{cases}$

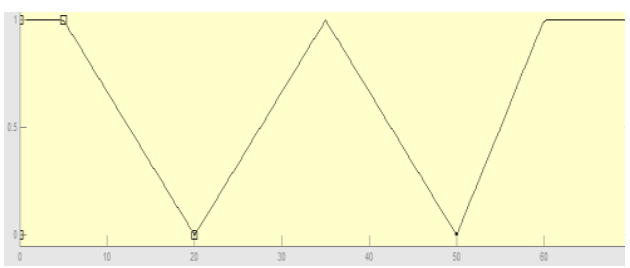

Gambar 3. Fungsi Keanggotaan Variabel Bibit Kayu Manis

c) Proses Penanaman Tunas terdiri dari 2 himpunan fuzzy, yaitu Langsung dan lihat Kondisi Bibit. Fungsi keanggotaan untuk variabel Proses Penanaman Tunas dirumuskan sebagai berikut.

$\mu$ Langsung[x]

$$
=\left\{\begin{array}{llr}
1 & ; & x \leq 25 \\
\frac{55-x}{55-25} & ; 25 \leq x \leq 55 \\
0 & ; & x \geq 55
\end{array}\right.
$$

$\mu$ lihat Kondisi Bibit[x]

$$
=\left\{\begin{array}{llr}
0 & ; & x \leq 55 \\
\frac{x-55}{80-55} & ; & 55 \leq x \leq 80 \\
1 & ; & x \geq 80
\end{array}\right.
$$

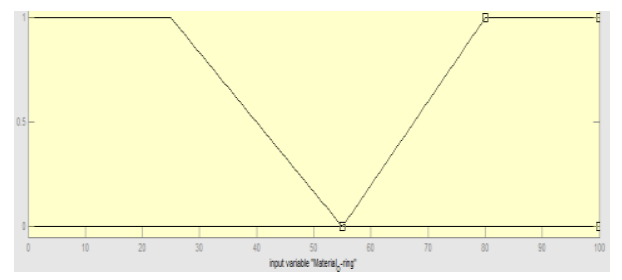

Gambar 4. Fungsi Keanggotaan Variabel Proses Penanaman Tunas 
Building of Informatics, Technology and Science (BITS)

Volume 3, No 3, December 2021, Page 141-147

ISSN 2684-8910 (media cetak)

ISSN 2685-3310 (media online)

DOI 10.47065/bits.v3i3.1014

d) Pemeliharaan terdiri dari 3 himpunan fuzzy, yaitu tidak pernah, Jarang, dan Rutin. Fungsi keanggotaan untuk variabel Pemeliharaan dirumuskan sebagai berikut.

$\mu$ Tidak Pernah $[\mathrm{x}]$

$= \begin{cases}0 & ; \mathrm{x} \leq 50 \text { atau } \mathrm{x} \geq 80 \\ \frac{\mathrm{x}-50}{65-80} & ; 50 \leq \mathrm{x} \leq 65 \\ \frac{80-\mathrm{x}}{80-65} & ; 65 \leq \mathrm{x} \leq 80\end{cases}$

$\mu \operatorname{Jarang}[\mathrm{x}]$

$=\left\{\begin{array}{llr}1 & ; & x \leq 35 \\ \frac{50-x}{50-35} & ; & 35 \leq x \leq 50 \\ 0 & ; & x \geq 50\end{array}\right.$

$\mu \operatorname{Rutin}[\mathrm{x}]$

$= \begin{cases}0 & ; \mathrm{x} \leq 80 \\ \frac{\mathrm{x}-80}{100-80} & ; 80 \leq \mathrm{x} \leq 100 \\ 1 & ; 100 \leq \mathrm{x} \leq 120\end{cases}$

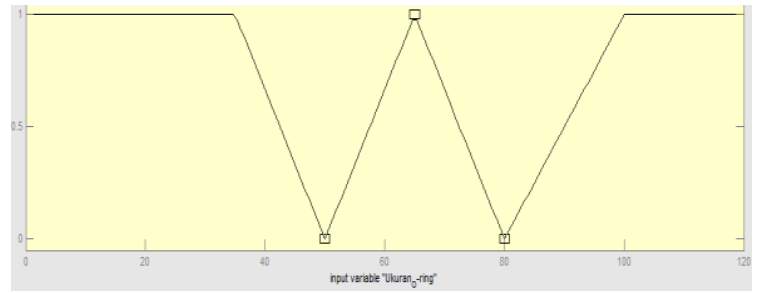

Gambar 5. Fungsi Keanggotaan Variabel Pemeliharaan

e) Keputusan Pemilihan Bibit Unggul merupakan variabel output yangterdiri dari 3 himpunan fuzzy, yaitu Tidak memuaskan, Memuaskan, dan Sangat Memuaskan. Fungsi keanggotaan untuk variabel Keputusan Pemilihan Bibit Unggul dirumuskan sebagai berikut.

$\mu$ Tidak Memuaskan[x]

$= \begin{cases}0 & ; \mathrm{x} \leq 40 \text { atau } \mathrm{x} \geq 70 \\ \frac{\mathrm{x}-40}{55-40} & ; 40 \leq \mathrm{x} \leq 55 \\ \frac{55-\mathrm{x}}{70-55} & ; 55 \leq \mathrm{x} \leq 70\end{cases}$

$\mu$ Memuaskan[x]

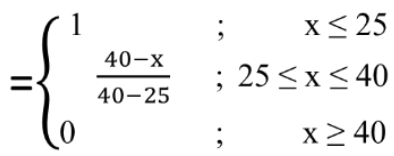

$\mu$ Sangat Memuaskan $[\mathrm{x}]$

$= \begin{cases}0 & ; \quad x \leq 70 \\ \frac{x-70}{85-70} & ; 70 \leq x \leq 85 \\ 1 & ; 85 \leq x \leq 70\end{cases}$

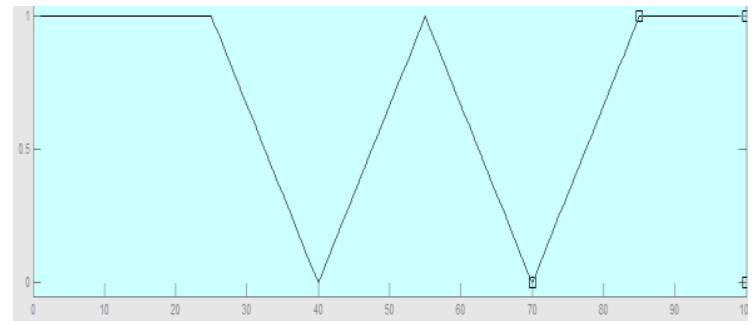

Gambar 6. Fungsi Variabel Keputusan Pemilihan Bibit Unggul

Setelah tahap fuzzifikasi, maka selanjutnya akan dilakukan pembentukan basis pengetahuan fuzzy. Aturanaturan yang terbentuk dapat disajikan dalam tabel berikut ini. 
Building of Informatics, Technology and Science (BITS)

Volume 3, No 3, December 2021, Page 141-147

ISSN 2684-8910 (media cetak)

ISSN 2685-3310 (media online)

DOI 10.47065/bits.v3i3.1014

Tabel 3. Basis Aturan

\begin{tabular}{|c|c|c|c|c|c|c|}
\hline Aturan & $\begin{array}{c}\text { Lahan } \\
\text { Tanaman }\end{array}$ & $\begin{array}{c}\text { Bibit } \\
\text { Kayu } \\
\text { Manis }\end{array}$ & Proses Penanaman Tunas & $\begin{array}{c}\text { Pemelihar } \\
\text { aan kayu } \\
\text { Manis }\end{array}$ & $\begin{array}{c}\text { Fungsi } \\
\text { Implikasi }\end{array}$ & Harga Jual $O$-ring \\
\hline R1 & Sedang & Biasa & Langsung & Jarang & $\rightarrow$ & Tidak Memuaskan \\
\hline R2 & Sedang & Biasa & Langsung & Jarang & $\rightarrow$ & Memuaskan \\
\hline R3 & Sedang & Biasa & Langsung & Jarang & $\rightarrow$ & Sangat Memuaskan \\
\hline $\mathrm{R} 4$ & Luas & Biasa & Langsung & Jarang & $\rightarrow$ & Tidak Memuaskan \\
\hline R5 & Luas & Biasa & Langsung & Jarang & $\rightarrow$ & Memuaskan \\
\hline R6 & Luas & Biasa & Langsung & Jarang & $\rightarrow$ & Sangat Memuaskan \\
\hline R7 & Sedang & Sedang & Langsung & Jarang & $\rightarrow$ & Tidak Memuaskan \\
\hline $\mathrm{R} 8$ & Sedang & Sedang & Langsung & Jarang & $\rightarrow$ & Memuaskan \\
\hline R9 & Sedang & Sedang & Langsung & Jarang & $\rightarrow$ & Mahal \\
\hline $\mathrm{R} 10$ & Luas & Sedang & Langsung & Jarang & $\rightarrow$ & Murah \\
\hline R11 & Luas & Sedang & Langsung & Jarang & $\rightarrow$ & Memuaskan \\
\hline R12 & Luas & Sedang & Langsung & Jarang & $\rightarrow$ & Sangat Memuaskan \\
\hline R13 & Sedang & Super & Langsung & Jarang & $\rightarrow$ & Tidak Memuaskan \\
\hline R14 & Sedang & Super & Langsung & Jarang & $\rightarrow$ & Memuaskan \\
\hline $\mathrm{R} 15$ & Sedang & Super & Langsung & Jarang & $\rightarrow$ & Sangat Memuaskan \\
\hline R16 & Luas & Super & Langsung & Jarang & $\rightarrow$ & Tidak Memuaskan \\
\hline $\mathrm{R} 17$ & Luas & Super & Langsung & Jarang & $\rightarrow$ & Memuaskan \\
\hline R18 & Luas & Super & Langsung & Jarang & $\rightarrow$ & Mahal \\
\hline R19 & Sedang & Biasa & Sesuai Kondisi & Jarang & $\rightarrow$ & Tidak Memuaskan \\
\hline $\mathrm{R} 20$ & Sedang & Biasa & $\begin{array}{c}\text { Sesuai KondisiTahan } \\
\text { Panas }\end{array}$ & Jarang & $\rightarrow$ & Memuaskan \\
\hline $\mathrm{R} 21$ & Sedang & Biasa & Sesuai Kondisi & Jarang & $\rightarrow$ & Sangat Memuaskan \\
\hline $\mathrm{R} 22$ & Luas & Biasa & $\begin{array}{c}\text { Sesuai KondisiTahan } \\
\text { Panas }\end{array}$ & Jarang & $\rightarrow$ & Tidak Memuaskan \\
\hline $\mathrm{R} 23$ & Luas & Biasa & Sesuai Kondisi & Jarang & $\rightarrow$ & Memuaskan \\
\hline $\mathrm{R} 24$ & Luas & Biasa & $\begin{array}{c}\text { Sesuai KondisiTahan } \\
\text { Panas }\end{array}$ & Jarang & $\rightarrow$ & Sangat Memuaskan \\
\hline $\mathrm{R} 25$ & Sedang & Sedang & Sesuai Kondisi & Jarang & $\rightarrow$ & Tidak Memuaskan \\
\hline $\mathrm{R} 26$ & Sedang & Sedang & $\begin{array}{c}\text { Sesuai KondisiTahan } \\
\text { Panas }\end{array}$ & Jarang & $\rightarrow$ & Memuaskan \\
\hline $\mathrm{R} 27$ & Sedang & Sedang & Sesuai Kondisi & Jarang & $\rightarrow$ & Sangat Memuaskan \\
\hline $\mathrm{R} 28$ & Luas & Sedang & $\begin{array}{c}\text { Sesuai KondisiTahan } \\
\text { Panas }\end{array}$ & Jarang & $\rightarrow$ & Tidak Memuaskan \\
\hline R29 & Luas & Sedang & Sesuai Kondisi & Jarang & $\rightarrow$ & Memuaskan \\
\hline $\mathrm{R} 30$ & Luas & Sedang & $\begin{array}{c}\text { Sesuai KondisiTahan } \\
\text { Panas }\end{array}$ & Jarang & $\rightarrow$ & Sangat Memuaskan \\
\hline
\end{tabular}

Langkah selanjutnya adalah perhitungan nilai akhir Defuzifikasi untuk mencari nilai output. Hasil masing masing pencarian nilai $\mathrm{x}$ diantaranya:

a) Nilai X lahan Pertanian

b) Nilai X Bibit Kayu Mani

$$
\begin{aligned}
& =35 \\
& =(x-a) /(b-a) \\
& =(35-30) /(40-30) \\
& =5 / 10 \\
& =0,5
\end{aligned}
$$

$$
\begin{aligned}
& =65 \\
& =(x-a) /(b-a) \\
& =(35-30) /(40-30) \\
& =5 / 10 \\
& =0,5
\end{aligned}
$$

c) Nilai X proses Penenaman Tunas

$$
\begin{aligned}
& =85 \\
& =(x-a) /(b-a) \\
& =(85-55) /(85-55) \\
& =30 / 30 \\
& =1 \\
& =90 \\
& =(x-a) /(b-a) \\
& =(90-80) /(100-80)
\end{aligned}
$$

d) Nilai X Pemeliharaan Kayu Manis 


$$
\begin{aligned}
& =10 / 20 \\
& =0,5
\end{aligned}
$$

Tabel 4. Hasil Akhir

\begin{tabular}{lll}
\hline No. & Nilai Inputan & Hasil \\
\hline 1 & 35 & 0,5 \\
2 & 65 & 0,5 \\
3 & 85 & 1 \\
4 & 90 & 0,5 \\
\hline
\end{tabular}

Berdasarkan nilai tabel diatas maka hasil output terakhir berupa penginputan nilai masing masing variabel yang digunakan. Ketetapan logika Fuzzy memperoleh nilai Akhir burupa nilai 0 sampai angka 1.

\section{KESIMPULAN}

Berdasarkan pembahasan penelitian dan analisa telah yang dilakukan, maka dapat disimpulkan untuk menentukan hasil pengambilan keputusan dalam Pemilihan Bibit kulit Manis membutuhkan variabel input dan variabel output Lahan tanaman, bibit kayu manis, proses penanaman tunas, dan pemeliharaan kayu manis menjadi output berupa hasil keputusan yaitu Sangat Memuaskan, memuaskan dan Tidak Memuaskan. Dari penelitian ini adalah logika fuzzy metode Mamdani bisa diterapkan dalam pengambilan keputusan Pemilihat Bibit Unggul Kulit manis dengan memasukkan Lahan tanaman, bibit kayu manis, proses penanaman tunas, dan pemeliharaan kayu manis. Untuk mengetahui Kapasitas Nilai X dalam pengambilan keputusan Pemilihat Bibit Unggul Kulit manis hanya dibutuhkan nilai masukkan yang di input kedalam Software Matlab dan menghasilkan nilai Output.

\section{REFERENCES}

[1] Rizki, Sestri Novia. (2018). Fuzzy logic memprediksi tingkat kecelakaan kerja pada PT.Galang Kapal di kota Batam. Digital Zone: Jurnal Teknologi Informasi dan Komunikasi, 9(2), 151-161. https://doi.org/10.31849/digitalzone.v9i2.1980

[2] Auditya, L., Kartiko, C., \& Wiguna, C. (2020). Jurnal Edik Informatika Jurnal Edik Informatika. Penelitian Bidang Komputer Sains dan Pendidikan Informatika, 7(1), 9-18.

Jarti, N., \& Lestari Putri, W. (2020). Penerapan Fuzzy Inference System Pemilihan Desain Interior. JURTEKSI (Jurnal Teknologi dan Sistem Informasi), 7(1), 75-82. https://doi.org/10.33330/jurteksi.v7i1.921

[3] Pangaribowo, T. (2015). Perancangan Simulasi Kendali Valve Dengan Algoritma Logika Fuzzy Menggunakan Bahasa Visual Basic. Teknologi Elektro, 6(2), 123-135.

[4] Jarti, N., \& Lestari Putri, W. (2020). Penerapan Fuzzy Inference System Pemilihan Desain Interior. JURTEKSI (Jurnal Teknologi dan Sistem Informasi), 7(1), 75-82. https://doi.org/10.33330/jurteksi.v7i1.921

[5] Jufriadi, J., Nurcahyo, G. W., \& Sumijan, S. (2020). Logika Fuzzy dengan Metode Mamdani dalam Menentukan Tingkat Peminatan Tipe Motor Honda. Jurnal Informatika Ekonomi Bisnis, 3, 7-11. https://doi.org/10.37034/infeb.v3i1.60

[6] Rahakbauw, D. L., Rianekuay, F. J., \& Lesnussa, Y. A. (2019). Penerapan Metode Fuzzy Mamdani Untuk Memprediksi Jumlah Produksi Karet (Studi Kasus: Data Persediaan Dan Permintaan Produksi Karet Pada Ptp Nusantara Xiv (Persero) Kebun Awaya, Teluk Elpaputih, Maluku-Indonesia). Jurnal Ilmiah Matematika Dan Terapan, 16(1), 51-59. https://doi.org/10.22487/2540766x.2019.v16.i1.12764

[7] Rizki, Sesri Novia, \& Tipa, H. (2020). Implementasi Fuzzy Inference System Untuk Menentukan Tingkat Kriminalitas Di Kota Batam. Digital Zone: Jurnal Teknologi Informasi dan Komunikasi, 10(2), $206-221$. https://doi.org/10.31849/digitalzone.v10i2.3090

[8] Ramadhan, M. R., Waluya, S. B., \& Kharis, M. (2015). UNNES Journal of Mathematics. Ujm, 1(2252), 125-130.

[9] Vindensia, D., \& Utami, Y. (2018). Penerapan Fuzzy Inference System ( FIS ) Metode Mamdani dalam Pemilihan Jurusan Perguruan Tinggi. Publikasi Jurnal \& Penelitian Teknik Informatika, 2(April 2018).

[10] Laia, O., \& Marpaung, P. (2021). Penerapan Logika Fuzzy Mamdani Untuk Memprediksi Stok Persediaan Barang Proyek ( Studi Kasus: Pt . Andhy Putra Medan ). JIKOMSI [Jurnal Ilmu Komputer dan Sistem Informasi], 3(3), 48-59. http://ejournal.sisfokomtek.org/index.php/jikom/article/view/89/77

[11] Nizar, H., Shafira, A. S., Aufaresa, J., Awliya, M. A., \& Athiyah, U. (2021). Perbandingan Metode Logika Fuzzy Untuk Diagnosa Penyakit Diabetes. Explore:Jurnal Sistem informasi dan telematika, 12(1), 37. https://doi.org/10.36448/jsit.v12i1.1763

[12] Charolina, Y. (2016). Sistem Pendukung Keputusan Untuk Menentukan Pemberian Bonus Tahunan Menggunakan Metode Fuzzy Logic Tipe Mamdani. Teknologi Informasi, 12(2), 42-53.

[13] Maryaningsih, Siswanto, \& Masterjon. (2013). Metode Logika Fuzzy Tsukamoto Dalam Sistem Pengambilan Keputusan Penerimaan Beasiswa. Media Infotama, 9(1), 140-165.

[14] Fernandez, A., \& Herrera, F. (2012). Linguistic Fuzzy Rules in Data Mining: Follow-Up Mamdani Fuzzy Modeling Principle. Combining Experimentation and Theory, 103-122.

[15] Sumiati, Sigit, H. T., \& Kapuji, A. (2014). Mamdani Fuzzy Inference System Application Setting For Trafic Lights. International Journal of Application or Innovation in Engineering \& Management (IJAIEM), 3(10), 56-62.

[16] Apriyanti, N., \& Aksad, H. (2013). Penerapan Metode Fuzzy Mamdani dalam Perencanaan Produksi Roti. Jurnal PROGRESIF, 9(1), 885-898.[17]

[17] Minarni, \& Aldyanto, F. (2016). Prediksi Jumlah Produksi Roti Menggunakan Metode Logika Fuzzy. Teknologi Informasi, 4(2), 59-65. 